\title{
The Expression of PI3K, AKT, $\beta$-Catenin and VEGFR2 in Medulloblastoma
}

\author{
Xiao Lin', Yu Li ${ }^{1,2,3 *}$ \\ ${ }^{1}$ Department of Pathology, Chongqing Medical University, Chongqing, China \\ ${ }^{2}$ Chongqing Key Laboratory of Neurobiology, Chongqing Medical University, Chongqing, China \\ ${ }^{3}$ Institute of Neuroscience, Chongqing Medical University, Chongqing, China \\ Email: 1x_cq200@126.com, *630761918@qq.com
}

How to cite this paper: Lin, $\mathrm{X}$. and $\mathrm{Li}, \mathrm{Y}$. (2017) The Expression of PI3K, AKT, $\beta$-Catenin and VEGFR2 in Medulloblastoma. Journal of Biosciences and Medicines, 5, 32-38.

https://doi.org/10.4236/jbm.2017.53004

Received: February 21, 2017

Accepted: March 7, 2017

Published: March 10, 2017

\begin{abstract}
Medulloblastoma (MB) is common tumor of the central nervous system in children. It's reported that PI3K/AKT and Wnt signal pathway have important roles in MB. This study aims to investigate the expression of PI3K, AKT, $B$-catenin and VEGFR-2 in MB to find a new pathway for MB. A total of 33 $\mathrm{MB}$ and 17 control brain cases were retrospectively evaluate $\mathrm{d}$ for PI3K, AKT, $\beta$-catenin and VEGFR-2 expression by immunohistochemical staining, and the relationship with clinical feature were analyzed. The positive rate of PI3K, AKT, $\beta$-catenin and VEGFR- 2 in $33 \mathrm{MB}$ were significantly greater than those in control group $(P<0.05)$, and significant positive correlation was found between PI3K, AKT, $\beta$-catenin and VEGFR-2 each other in MB $(P<0.05)$. Moreover, the clinical data, such as age, gender, tumor size was no significant correlation between the expression of PI3K, AKT, $\beta$-catenin and VEGFR-2 was found $(P<0.05)$.
\end{abstract}

\section{Keywords}

PI3K, AKT, $\beta$-Catenin, VEGFR2, Medulloblastoma

\section{Introduction}

VEGF family and their receptor VEGFR are affected especially in develop and matastasis of tumor. VEGFR2 Which could adjust reaction of VEGF in intercellular [1], and was considered that it was major medium for promoting angiogenesis and enhancing rasopermeability, which participating in regulation of multi-signal pathway each other. It was reported that VEGF and receptor VEGFR2 are formed to dimmer in extracellular, which make its intracellular phosphorylation, which further phosphorylate PI3K, activate a series of signal pathway. Recent years, it has been become the hotspot that PI3K/AKT and Wnt signal path- 
way are affected in genesis, development, therapy and prognosis in tumors. The published studies focused on breast cancer [2], ovarian cancer [2], endometrial cancer [3], nasopharyngeal cancer [4], human gliblastomas [5], etc.

Furthermore, present studies were responsible for the occurrence and development of tumor by adjusting Wnt signal pathway. MB is the most common maliganat brain tumor in children. The relevance of PI3K/AKT and Wnt signal pathway have not yet been sufficiently elucidated in $\mathrm{MB}$, and further investigations are required. The aim of this study is to investigate the expression and correlation of PI3K, AKT, $\beta$-catenin and VEGFR-2 in $33 \mathrm{MB}$ and 17 control brain tussle by immunohistochemical staining.

\section{Materials and Methods}

\subsection{Patients and Tissues}

MB tissue samples from 33 patients were diagnosed between 2005 and 2009 at Department of Pathology in Chongqing Medical University. Clinical data were obtained from retrospective review.

\subsection{Histopathology}

The diagnoses of MB were based on a combination of clinical information, morphologic examination and immunohistochemical results. All cases were classified according to World Health Organization (WHO) 2007 as classical [6].

\subsection{Immunohistochemistry}

PI3K, AKT, $\beta$-catenin and VEGFR-2 were analyzed by immunohistochemistry. Antigen retrieval was used to enhance PI3K, AKT, $\beta$-catenin and VEGFR-2 expression by immunohistochemical staining by high pressure in citrate buffer(ph 6.0) for $3 \mathrm{~min}$. Then the sections incubated with rabbit monoclonal anti-PI3K (1:100 SANTA CRUZ company), anti-AKT(1:100 SANTA CRUZ company), mouse monoclonal anti- $\beta$-catenin (1:100 SANTA CRUZ company), anti-VEGFR2 (1:100 SANTA CRUZ company) over-night at $4^{\circ} \mathrm{C}$. Slides were stained with $\mathrm{DAB}$ until desired stain intensity developed and mounted before observation by light microscopy.

\subsection{Assessment of Immunoreactivity}

The positive reaction is defined as discrete localization of the chromogen in the cytoplasm/nucleus of all slides. The intensity of cytoplasm/nucleus reaction is graded as negative (- positive cells percentage bellow $10 \%)$, mild positive (+ positive cells percentage is $11 \%-30 \%)$, moderate positive (++ positive cells percentage is $31 \%-70 \%)$, and strong positive (+++ positive cells are above $70 \%$ ) [7].

\subsection{Data Analysis}

$\mathrm{X}^{2}$ fisher's exact test was applied using the SPSS 10.0 to determine the significance of difference in expression of PI3K, AKT, $\beta$-catenin and VEGFR-2. Spearman correlation coefficients were determined for comparisons between immu- 
nohistochemical expression data of PI3K, AKT, $\beta$-catenin and VEGFR-2. The results were considered as statistically significant difference when $P<0.05$.

\section{Result}

1) The immunohistochemical expression of PI3K, AKT, $\beta$-catenin, VEGFR2 in $\mathrm{MB}$ and control brain tissues group:

We employed immunohistochemistry to evaluate the expression of PI3K, $\mathrm{AKT}, \beta$-catenin, VEGFR2 in $\mathrm{MB}$ and control group. The positive staining of PI3K was found in 31/33 (93.9\%) cases of human MB (Figure 1), and 8/17 $(47.1 \%)$ cases in control brain tissues group. The positive staining of AKT was found in $27 / 33(81.8 \%)$ cases of human MB (Figure 2), and $8 / 17(47.1 \%)$ in control group. Moreover, the positive staining of $\beta$-catenin was found in $22 / 33$ $(66.7 \%)$ cases of human MB (Figure 3 ), and $2 / 17(11.8 \%)$ in control group. The positive staining of VEGFR2 was found in 29/33 (87.9) cases of MB (Figure 4), and $3 / 17$ (17.6\%) in control group. On all accounts, the prevalence of PI3K, $\mathrm{AKT}, \beta$-catenin and VEGFR2 positive expression in MB were significantly greater than those in control brain group $(P<0.05)$ (Table 1$)$.

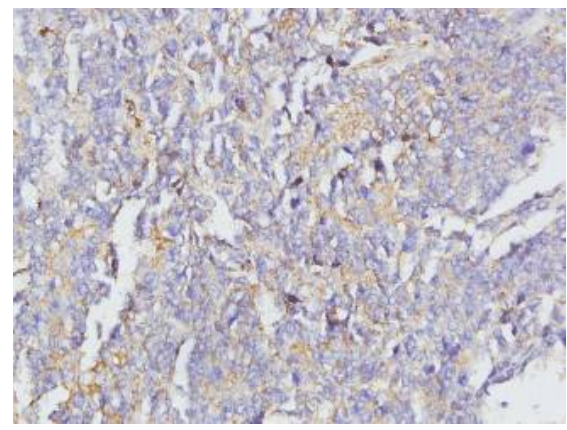

Figure 1. The positive staining of PI3K in MB $(\times 200)$.

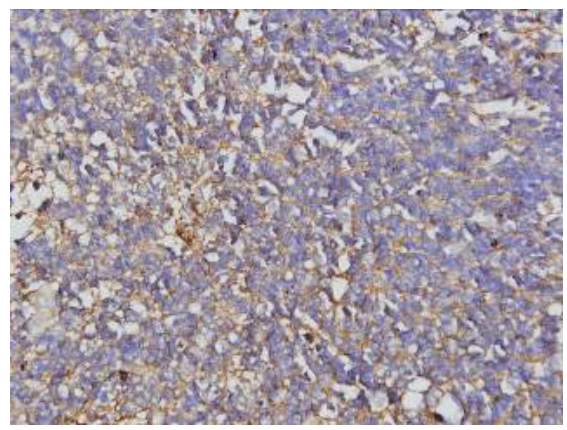

Figure 2. The positive staining of AKT in MB (×200)

Table 1. Expression of PI3K, AKT, $\beta$-catenin, VEGFR2 in medulloblastoma and control group.

\begin{tabular}{|c|c|c|c|c|c|c|c|c|c|c|c|c|c|c|c|c|c|}
\hline \multirow{2}{*}{ Group } & \multirow{2}{*}{ Case } & \multicolumn{4}{|c|}{ PI3K } & \multicolumn{4}{|c|}{ AKT } & \multicolumn{4}{|c|}{$\beta$-catenin } & \multicolumn{4}{|c|}{ VEGFR2 } \\
\hline & & +++ & ++ & + & - & +++ & ++ & + & - & +++ & ++ & + & - & +++ & ++ & + & - \\
\hline Medulloblastoma & 33 & 15 & 10 & 6 & 2 & 6 & 12 & 9 & 6 & 7 & 5 & 10 & 11 & 17 & 7 & 5 & 4 \\
\hline Control Group & 17 & 1 & 2 & 5 & 9 & 1 & 2 & 5 & 9 & 0 & 0 & 2 & 15 & 0 & 1 & 2 & 14 \\
\hline$P$ value & & \multicolumn{4}{|c|}{$<0.05$} & \multicolumn{4}{|c|}{$<0.05$} & \multicolumn{4}{|c|}{$<0.05$} & \multicolumn{4}{|c|}{$<0.05$} \\
\hline
\end{tabular}




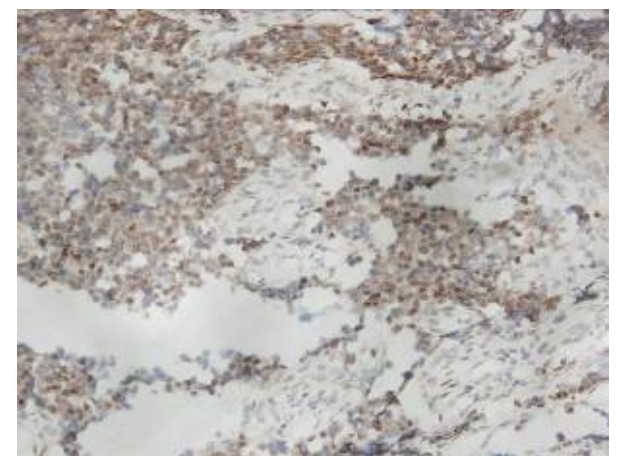

Figure 3. The positive staining of $\beta$-catenin in $\mathrm{MB}(\times 200)$.

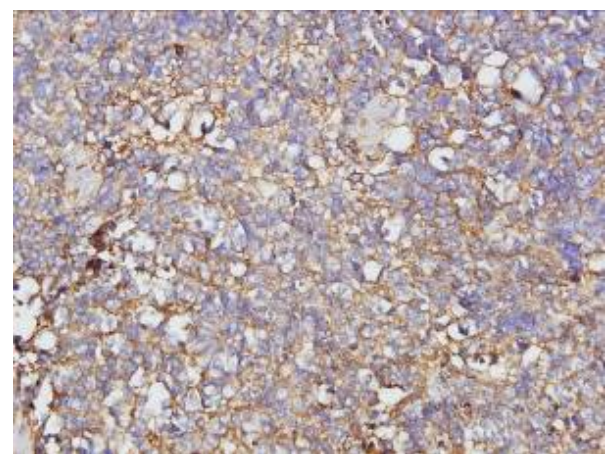

Figure 4. The positive staining of VEGFR2 in MB $(\times 200)$.

2) The relation between protein expression of PI3K, AKT, $\beta$-catenin, and VEGFR2 in MB with each other:

Significant positive correlations were found between PI3K and AKT $(\mathrm{r}=$ $0.375, P=0.032)$; PI3K and $\beta$-catenin $(\mathrm{r}=0.544, P=0.001)$; meanwhile, significant positive correlation were found between PI3K and VEGFR2 $(\mathrm{r}=0.604, P=$ $0.000)$, AKT and $\beta$-catenin $(\mathrm{r}=0.405, P=0.019)$; AKT and VEGFR2 $(\mathrm{r}=0.488$, $P=0.004)$ in MB by spearman's correlation test.

3) The relation between protein expression of PI3K, AKT, $\beta$-catenin, and VEGFR2 in MB with clinical characteristics:

No significant correlations were found between expression of PI3K, AKT, $\beta$-catenin and VEGFR2 with clinical characteristics of pathological type $(P>$ 0.05) (Table 2).

4) The relation between protein expression of PI3K, AKT, $\beta$-catenin, and VEGFR2 in MB with different kinds of MB (classic, desmoplastic, MBEN/large cell and anaplastic $\mathrm{MB}$ ):

No significant difference was found in the expression of PI3K, AKT, $\beta$-catenin and VEGFR2 in different pathological type MB $(P>0.05)$ (Table 3$)$

\section{Discussion}

The recent study shows that multi-signal pathway and VEGF family have important effect in occurrence and development of tumor, furthermore, VEGFR2 participate in regulating multi-signal pathway. PI3K/AKT signal pathway and Wnt/ $\beta$-catenin signal pathway were considered to be important roles in it, which were 
Table 2. Relation between expression of PI3K, AKT, $\beta$-catenin, VEGFR2 with clinical characteristics in MB.

\begin{tabular}{|c|c|c|c|c|c|c|c|c|c|}
\hline \multirow{2}{*}{ Group } & & \multicolumn{2}{|c|}{ PI3K } & \multicolumn{2}{|c|}{ AKT } & \multicolumn{2}{|c|}{$\beta$-catenin } & \multicolumn{2}{|c|}{ VEGFR2 } \\
\hline & & + & - & + & - & + & - & + & - \\
\hline \multirow{2}{*}{ Gender } & Male & 18 & 1 & 16 & 4 & 13 & 6 & 17 & 2 \\
\hline & Female & 13 & 1 & 11 & 2 & 9 & 5 & 12 & 2 \\
\hline \multirow{2}{*}{ Age } & $\leq 3 \mathrm{y}$ & 5 & 0 & 4 & 1 & 4 & 1 & 4 & 1 \\
\hline & $>3 y$ & 26 & 2 & 23 & 5 & 18 & 10 & 25 & 3 \\
\hline \multirow{2}{*}{ Tumor } & $\leq 1.5 \mathrm{~cm}^{3}$ & 11 & 1 & 9 & 3 & 8 & 4 & 11 & 1 \\
\hline & $>1.5 \mathrm{~cm}^{3}$ & 20 & 1 & 18 & 3 & 14 & 7 & 18 & 3 \\
\hline$P$ value & & \multicolumn{2}{|c|}{$>0.05$} & \multicolumn{2}{|c|}{$>0.05$} & \multicolumn{2}{|c|}{$>0.05$} & \multicolumn{2}{|c|}{$>0.05$} \\
\hline
\end{tabular}

Table 3. Relation between expression of PI3K, AKT, $\beta$-catenin, VEGFR2 with type of MB.

\begin{tabular}{|c|c|c|c|c|c|c|c|c|c|c|c|c|c|c|c|c|c|c|c|c|}
\hline \multirow{2}{*}{ Group } & \multicolumn{5}{|c|}{ PI3K } & \multicolumn{5}{|c|}{$\mathrm{AKT}$} & \multicolumn{5}{|c|}{$\beta$-catenin } & \multicolumn{5}{|c|}{ VEGFR2 } \\
\hline & +++ & ++ & + & - & $\mathrm{P}$ & +++ & ++ & + & - & $\mathrm{P}$ & +++ & ++ & + & - & $\mathrm{P}$ & +++ & ++ & + & - & $\mathrm{P}$ \\
\hline Classic & 8 & 5 & 6 & 1 & \multirow[b]{3}{*}{$>0.05$} & 2 & 8 & 7 & 3 & \multirow[b]{3}{*}{$>0.05$} & 4 & 4 & 7 & 7 & \multirow[b]{3}{*}{$>0.05$} & 6 & 5 & 6 & 3 & \multirow{4}{*}{$>0.05$} \\
\hline Desmoplastic & 3 & 2 & 3 & 1 & & 2 & 3 & 3 & 1 & & 3 & 1 & 3 & 2 & & 8 & 0 & 0 & 1 & \\
\hline MBEN/large cell & 1 & 1 & 0 & 0 & & 1 & 0 & 0 & 1 & & 0 & 1 & 0 & 1 & & 0 & 1 & 0 & 1 & \\
\hline Anaplastic & 1 & 1 & 0 & 0 & & 1 & 0 & 0 & 1 & & 0 & 0 & 1 & 1 & & 1 & 1 & 0 & 0 & \\
\hline
\end{tabular}

found in nasopharyngeal cancer [8], colon cancer [9] and glioblastoma [10].

PI3K is a kind of kinase with differential phosphory lation of phosphatidylinositol 3-hydroxy and frequently activated in human cancer, which playing a crucial role in controlling cell proliferation, survival, and metastasis downstream of many growth factor receptors, it has been activated by the stimulation of phosphorylated 3-hydroxy on the inositol ring, and then producing secondary messengers PI-3, 4-P2, PI3, 4, 5-P3 to phosphorylated AKT on ser 473, ser308 to downstream target protein, involved in cell proliferation and an angiogenesis [11]. The current study presents that the signal pathway of PI3K/AKT plays important role as anti-apoptosis in appearance and development of several kinds of tumors. However, apoptosis is the major mode of inducing the malignancy cells to be dead and it is the major mechanism of the generation of resistance and antiradiation in the malignancy cells to both chemotherapy and radiotherapy. Therefore, it is so important that study the effect of signal pathway of PI3K/ AKT. We have chosen the $33 \mathrm{MB}$ samples which had been clearly treated and 17 brain tissues samples as control group to study the effect of PI3K/AKT signal pathway in MB by immunohistochemical methods. Our results showed that the positive rate of PI3K and AKT in these $33 \mathrm{MB} 93.2 \%, 81.8 \%$, respectively, while the positive rates are $47.1 \%, 47.1 \%$ in control group. Overexpression of PI3K and AKT protein are detected in MB compared with control group $(P<0.05)$. Our results suggested thatPI3K/AKT signal pathway would affect important impact in $\mathrm{MB}$, which are consistent to the experiment result of Wolfgang Hartmann [12].

$B$-catenin is a significant upstream factor in Wnt signal pathway, which forms 
multi-protein degradation compounds. After Wnt signal pathway was activated multi-protein degradation is degraded, to entrance a great quantity of $\beta$-catenin into cell nucleus, and form to complex with transcription factor Tcf/Lef, Which activated downstream target gene, lead to proliferation and metastasis of tumor [13]. Meanwhile, abnormal cumulation of $\beta$-catenin causes E-cadherin inactivation, which participates in inter-cellular conglutination and infiltrative growth of tumor cells.

Ellison [14] found that nucleus abnormal expression of $\beta$-catenin was closely related with no desmoplastic MB. Our results showed that the positive rate of $\beta$-catenin in $33 \mathrm{MB}$ is $66.7 \%$, but $11.8 \%$ in 17 control group, which has significant difference $(P<0.05)$.

Recent researches indicate that it caused angiogenesis and increased vascular permeability after VEGF combined to VEGFR which promoted infiltration and metastasis.

Dejana [15] indicated that VEGF would combine with VEGFR2, E-cadherin and $\beta$-catenin to promote, cell survivel. In our study, we also analyzed correlation of PI3K, AKT, $\beta$-catenin and VEGFR2 in MB. Our result showed the protein expression of PI3K, AKT, $\beta$-catenin and VEGFR2 pressents positive statistical significance correlation each other in $\mathrm{MB}(P<0.05)$, which confirmed the cooperation of PI3K, AKT, $\beta$-catenin and VEGFR2 in MB. The mechanism may be that the transmembrane complex formed with VEGFR2, E-cadherin and $\beta$-catenin actived PI3K, which phosphorylate AKT, which is due to GSK3 $\beta$ inavtiveted by phosphorylated at ser 9 locus in serine, as a result that reduce the degradation of $\beta$-catenin made by complex with APC, Axin and GSK $3 \beta$, which made $\beta$-catenin abnormal gather into nucleus, which stimulate to downstream gene, result in proliferation and metastasis. So, it's considered that $\mathrm{Wnt} / \beta$-catenin signal pathway play a direct important role in occur and develop of tumor. Meanwhile, PI3K/AKT signal pathway regulates it.

At the same time, we analyzed the correlation of expressions of PI3K, AKT, $\beta$-catenin and VEGFR2 between different kinds of MB (classic, desmoplastic, $\mathrm{MBEN} /$ large cell and anaplastic MB). The result illustrates that there is no significant difference in the expression of PI3K, AKT, $\beta$-catenin and VEGFR2 in different pathological type $\mathrm{MB}(P>0.05)$. Our results demonstrate there is no significant correlation between the PI3K, AKT, $\beta$-catenin, VEGFR2 with the difference of types of tumor cells, it may be the common pathway of tumor appearance.

In addition, we analyzed the correlation between expression of PI3K, AKT, $\beta$ catenin and clinic data such as grender, ages and tumor size. Our results show that there is no significant correlation among the expression of PI3K, AKT, $\beta$ catenin, VEGFR2, and the clinical data in MB $(P>0.05)$.

In summary, PI3K, AKT, $\beta$-catenin, VEGFR2 play synergy in the occurring and development of $\mathrm{MB}$ in order to promote the hyperplasia, metastasis and apoptosis of tumor cells, which may benefit the future target spot in therapy of MB. 


\section{References}

[1] Xue, G., Restuccia, D.F., Lan, Q., et al. (2012) Promotes Tumor Metastasis via Mediating Cross-Talk between PI3K/Akt and TGF- $\beta$ Signaling Axes. Cancer Discov, 2 , 248-259. https://doi.org/10.1158/2159-8290.CD-11-0270

[2] Liao, H., Zhou, Q., Gu, Y., et al. (2012) Ovarian Epithelian Tumor Cells and Metformin Inhibits the Effect through the Mtor Signaling Pathway. Oncol Rep, 27, 1873-1878.

[3] Yip, W.K. and Seow, H.F. (2012) Signaling by EGF Downregulates Membranous E-Cadherin and $\beta$-Catenin and Enhances Invasion in Nasopharyngeal Carcinoma Cells. Cancer Lett, 318, 162-172. https://doi.org/10.1016/j.canlet.2011.12.018

[4] Or, Y.Y., Hui, A.B., Tam, K.Y., et al. (2005) Characterization of Chromosome 3q and 12q Amplicons in Nasopharyngeal Carcinoma Cell Line. Int J Oncol, 26, 49-56.

[5] Knobbe, C.B., Kieslich, A.T. and Reifenberger, G. (2005) Genetic Alteration and Expression of the Phosphoinositol-3-Kinase/AKT Pathway Gene PIK3CA and PIKE in Human Gliobblastomas. Neuropathol Appl Neurpbiol, 31, 486-490. https://doi.org/10.1111/j.1365-2990.2005.00660.x

[6] Louis, D.N., Ohgaki, H., Wiestler, O.D., et al. (2007) The 2007 WHO Classification of Tumours of the Central Nervous System. Acta Neurpathol, 114, 97-109. https://doi.org/10.1007/s00401-007-0243-4

[7] Liao, S.J., Yuan, B., Hu, X.J., et al. (2008) The Expression of PDK/AKT/P-AKT and the Correlation with Ki67 in Cervical Cancer. Tumor, 28, 317-321.

[8] Morrison, J.A., Gulley, M.L., Pathmanathan, R., et al. (2004) Differential Signaling Pathways Are Activated in the Epstein-Barr Virus-Associated Malignancies Nasopharyngeal Carcinoma and Hodgkin Lymphoma. Cancer Res, 64, 5251-5260. https://doi.org/10.1158/0008-5472.CAN-04-0538

[9] He, X.C., Yin, T., Grindley, J.C., et al. (2007) PTEN-Deficient Intestinal Stem Cells Initiate Intestinal Polyposis. Nat Genet, 39, 189-198. https://doi.org/10.1038/ng1928

[10] Koul, D., Shen, R., Bergh, S., et al. (2006) Inhibition of AKt Survival Pathway by a Small-Molecule Inhibitor in Human Glioblastoma. Mol Cancer Ther, 5, 637-644. https://doi.org/10.1158/1535-7163.mct-05-0453

[11] Ba Va, J. and Nath, K.A. (1995) Endothelial Cell Heme Oxygenase and Ferritininduction in Ratlung by Hemoglobin in Vivo. Am J Physiol, 268, L321-L327.

[12] Hartmann, W., Digon Sontgerath, B., Koch, A., et al. (2006) Phosphatidylinositol 3'-Kinase/AKT Signaling Is Activated in MB Cell Proliferation and Is Associated with Reduced Expression of PTEN. Clin Cancer Res, 12, 3019-3027. https://doi.org/10.1158/1078-0432.CCR-05-2187

[13] Yamamoto, H., Kishida, S., Kishida, M., et al. (1999) Phosphorylation of Axin, a Wnt Signal Negative Regulator, by Glycogen Synthase Kinase- $3 \beta$ Regulates Its Stability. Biol Chem, 274, 10681-10684. https://doi.org/10.1074/jbc.274.16.10681

[14] Ellison, D.W., Onilude, O.E., Lindsey, J.C., et al. (2005) B-Catenin Status Predicts a Favorable Outcome in Childhood MB: The United Kingdom Children's Cancer Study Group Brain Tumor Committee. Journal of Clinical Oncology, 23, 7951-7957. https://doi.org/10.1200/JCO.2005.01.5479

[15] Dejana, E., Orsenigo, F. and Lampugnani, M.G. (2008) The Role of Adherent Junction and VE-Cadherin in the Control of Vascular Permeability. J Cell Sci, 121, 2115-2122. https://doi.org/10.1242/jcs.017897 
Submit or recommend next manuscript to SCIRP and we will provide best service for you:

Accepting pre-submission inquiries through Email, Facebook, LinkedIn, Twitter, etc. A wide selection of journals (inclusive of 9 subjects, more than 200 journals)

Providing 24-hour high-quality service

User-friendly online submission system

Fair and swift peer-review system

Efficient typesetting and proofreading procedure

Display of the result of downloads and visits, as well as the number of cited articles Maximum dissemination of your research work

Submit your manuscript at: http://papersubmission.scirp.org/

Or contact jbm@scirp.org 